\title{
Effect of Agricultural Seasons on Energy Intake: Evidence from Two Agro-Ecologically Different Rural Districts of India
}

\author{
D. J. Nithya, S. Raju, Aliza Pradhan \\ Leveraging Agriculture for Nutrition in South Asia, M. S. Swaminathan Research Foundation, Taramani Institutional Area, \\ Chennai, India \\ Email: djnithya@mssrf.res.in
}

How to cite this paper: Nithya, D.J., Raju, S. and Pradhan, A. (2018) Effect of Agricultural Seasons on Energy Intake: Evidence from Two Agro-Ecologically Different Rural Districts of India. Food and $\mathrm{Nu}$ trition Sciences, 9, 542-555.

https://doi.org/10.4236/fns.2018.95041

Received: March 21, 2018

Accepted: May 19, 2018

Published: May 22, 2018

Copyright $\odot 2018$ by authors and Scientific Research Publishing Inc. This work is licensed under the Creative Commons Attribution International License (CC BY 4.0).

http://creativecommons.org/licenses/by/4.0/

(c) (i) Open Access

\begin{abstract}
Seasonality is recognised as a constraint to agricultural production and food and nutrition security of rural households. It alters the energy intake from different groups of foods based on the availability. These variations in energy intake affect the nutritional status of the population. Eight villages in Wardha district of Maharashtra state and eleven villages in Koraput district of Odisha state were purposefully selected for the study. Foods consumed by households were collected using a semi-quantitative questionnaire in three rounds in 2013-14 and 2014-15 to cover the lean (January-April), planting (May-August) and harvest (September-December) periods in agriculture. Cereals (wheat and rice), pulses, roots and tubers, fats and sugars were consumed daily in Wardha. In Koraput, the daily diet included cereals (rice and finger millet), other vegetables, fats and sugars. Cereals supplied majority of the total energy intake in both the study area (63\% in Wardha and $85 \%$ in Koraput); the contribution is higher during lean period in Wardha and during planting in Koraput. Significant variation was found in the mean intake of food groups and the energy obtained from them between seasons except for few food groups. It was found to be positive during the planting season in Koraput and negative during lean period and harvest season when compared with the average energy intake across three seasons; in Wardha, energy intake was positive during harvest season followed by lean and was negative during planting season. It was also found that most small land holders ( $<2 \mathrm{ha}$ ) were affected by seasonality. The sourcing of foods and the energy contributed by them to the total energy intake also varied depending on seasons and majority of energy intake was sourced from public distribution system. Seasonality plays a crucial role in energy intake of individuals through fluctuation in availability and accessibil-
\end{abstract}


ity of food; this in turn will impact the nutritional status of the rural population. Energy requirement varies according to seasons as the type of agriculture activity differs. It is important to take seasonality into consideration while designing food-based approaches to combat the problem of undernutrition.

\section{Keywords}

Agricultural Seasons, Energy Intake, Landholding Size, Sourcing of Foods

\section{Introduction}

Asia has the highest population exposed to severe agro-climatic seasonality and the largest number of people at risk of seasonal energy stress [1]. Most rural populations in developing countries suffer from seasonal energy stress because of fluctuation in their access to food, either in absolute terms, such as during the pre-harvest decline in food availability, or in relative terms, because of the increased energy output needed for peak agricultural work, which has been recognized as a contributor to nutrition and health problems [2].

Agriculture plays a vital role in India's economy and over 57.8 per cent of the rural households depend on agriculture as their principal means of livelihood [3]. Seasonality is recognised as a constraint to agricultural production and to household food and nutrition security [4]. Many studies have reported the influence of seasonal fluctuations on food availability, energy and nutrient intake, as well as the body weight of adults and growth of children.

Food security among rural agricultural households during lean seasons is challenging as majority of them rely on rain fed agriculture coupled with poor post season storage capacity or limited market opportunities [5]. The variation in the price of commodities also plays a wider role in household food security. Locke et al. [6] conducted a study on agriculture community and stated that the availability of fruits and vegetables in rural communities is high during harvest seasons when farmers markets are flooded with fresh locally grown produce and heightened supply leads to lower prices. Considerable seasonal variation was observed in energy sources in rural areas, less so in urban areas [7].

Larger variation in food consumption between seasons has been reported and this has to be taken into account for dietary studies as intake of nutrients differ between seasons depending on availability of foods [8]. Shively and Hao [9] demonstrated that in Uganda, the planting season was the period of low dietary diversity. There are also other factors aggravating seasonal stress, such as socio economic gradient, gender differences, division of labor etc. The effect of seasonality on food availability and nutritional status is aggravated if the seasonal burdens are unequally distributed between social groups within the society [2]. Pastore et al. [10] reported that in the early pre-harvest season, food stocks of poor households were 6.5 times smaller than those of better-off families. In con 
trast to the above studies, Tin-May-Than and Ba-Aye [11] indicated that food intake in Burmese farming community is not a limiting factor in energy expenditure in different seasons.

Against this backdrop, the present paper assesses the food consumption and energy intake of rural households in the Wardha district of Maharashtra state and Koraput district of Odisha state in India. Figure 1 shows the study locations in India. The data used in the present paper was collected as a part of baseline survey under a "Farming System for Nutrition (FSN)" study. Agriculture is the primary occupation of the population in both the study locations, implying that agriculture could be a potential solution to combat nutrition and health inadequacies [12]. Agriculture production fluctuates according to seasons and this impacts food availability and food prices which in turn affects food security and the nutritional status. The objective of the present paper is to assess relationship of agriculture seasons and land holding on energy intake and the effect of seasonality on sourcing of foods and the energy obtained from them.

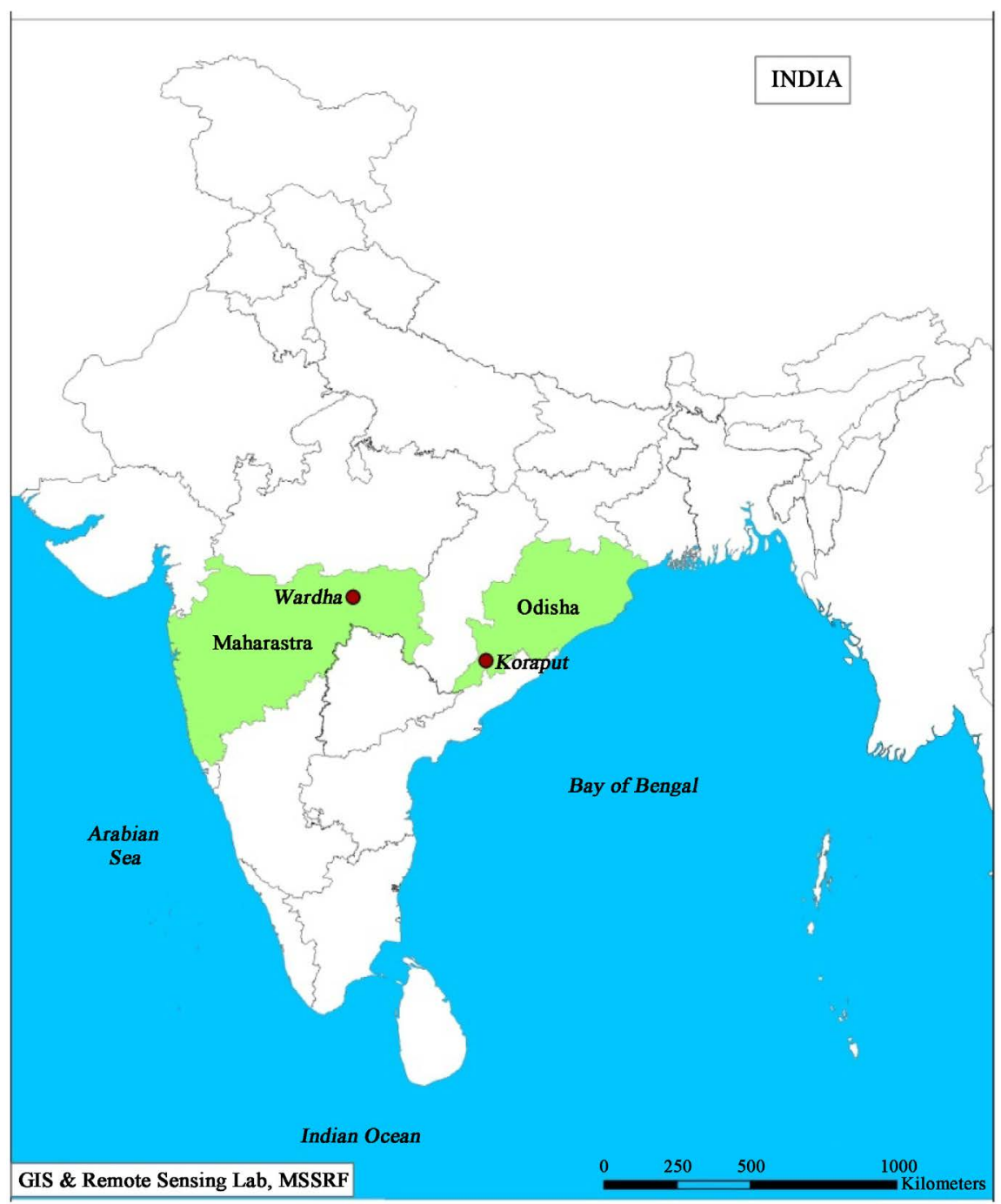

Figure 1. India map showing FSN study locations. 


\section{Materials and Method}

\subsection{Study Area}

The study locations were purposively selected in 2013, due to their characteristic contrast with regard to agro-climatic and socio-economic status, landholding pattern, farming practices and food consumption pattern. Information on the study locations have been previously reported by Das et al. [13] and Nagarajan et al. [14]. Both study areas are characterized by rain-fed farming and high levels of undernutrition [12]. Eight villages having 822 households with a population of 3287 in Wardha district, Maharashtra state and eleven villages having 921 households with a population of 3958 in Koraput district, Odisha state were identified for study. A detailed baseline survey was undertaken in 2014, to understand the demographic, socioeconomic, nutritional status and consumption pattern of the population.

\subsection{Food Consumption Pattern}

The consumption of different foods based on monthly recall was collected using a semi-quantitative questionnaire in 2013-15. Data were collected at three points of time in a year to capture agricultural seasonal variations in food consumption; Lean (January-April), planting (May-August) and harvest (September-December) periods in agriculture. The foods were grouped based on the classification given by Indian Council of Medical Research, National Institute for Nutrition, Hyderabad, India. The energy composition of foods were obtained from the "Nutritive value of Indian Foods” (2012) published by National Institute for Nutrition, Hyderabad.

\subsection{Landholding Size}

Landholding is the source of income, employment and economic security of most rural people. Since land is the productive asset which mainly determines income distribution and thus access to food in the rural areas; nutrition among rural people is closely related to the size of the land holdings [4]. In the study areas, landholdings are defined as operational land which includes own land as well as leased-in land. The details of the landholding sizes of the study areas are given in Table 1 . The effect of landholding size on the energy intake is analysed and presented in the paper.

\subsection{Statistical Analysis}

SPSS (IBM Version 20) and Stata (12.1) were the statistical packages used. Paired $\mathrm{T}$ test was performed to assess the significance of food and energy intake between seasons.

\section{Results and Discussion}

\subsection{Socio-Demographic Profile of the Population}

The characteristics of the households in the study area are given in Table 1. Both the study locations are dominated by Scheduled tribes, $49 \%$ in Wardha and $44 \%$ 
Table 1. Characteristics of the population in the study area.

\begin{tabular}{|c|c|c|}
\hline & $\begin{array}{l}\text { Wardha } \\
\mathrm{n}=822\end{array}$ & $\begin{array}{c}\text { Koraput } \\
\mathrm{n}=921\end{array}$ \\
\hline \multicolumn{3}{|c|}{ Social Group } \\
\hline Scheduled Caste & $107(13.0)$ & $120(13.0)$ \\
\hline Scheduled Tribe & $401(48.8)$ & $406(44.1)$ \\
\hline Other Backward Castes & $142(17.3)$ & $372(40.4)$ \\
\hline Others & $172(20.9)$ & $23(2.5)$ \\
\hline \multicolumn{3}{|c|}{ Age Group } \\
\hline 0 to 5 Years & $282(8.6)$ & $472(11.9)$ \\
\hline 6 to 11 Years & $255(7.8)$ & $588(14.9)$ \\
\hline 12 to 17 Years & $345(10.0)$ & $501(12.7)$ \\
\hline 18 to 44 Years & $1435(43.7)$ & $1524(38.5)$ \\
\hline$>=45$ Years & $970(29.5)$ & $873(22.1)$ \\
\hline \multicolumn{3}{|c|}{ Gender } \\
\hline Male & $1722(52.4)$ & $1874(47.3)$ \\
\hline Female & $1565(47.6)$ & $2084(52.7)$ \\
\hline \multicolumn{3}{|c|}{ Head of the Household Occupation } \\
\hline Cultivation & $470(57.2)$ & $520(56.5)$ \\
\hline Agriculture Wage Labour & $314(38.2)$ & $122(13.3)$ \\
\hline Artisans/Independent Work & $9(1.1)$ & $13(1.4)$ \\
\hline Non-Agriculture Wage labour & $6(0.7)$ & $173(18.8)$ \\
\hline Others & $23(2.8)$ & $93(10.1)$ \\
\hline \multicolumn{3}{|c|}{ Head of the Household Education status } \\
\hline Illiterate & $182(22.1)$ & $609(66.1)$ \\
\hline Primary & $378(46.0)$ & $239(26.0)$ \\
\hline Upper Primary & $189(23.0)$ & $60(6.5)$ \\
\hline Higher Secondary & $49(6.0)$ & $4(0.4)$ \\
\hline Graduate \& above & $24(2.9)$ & $9(1.0)$ \\
\hline \multicolumn{3}{|c|}{ Land Classification } \\
\hline Landless & $306(37.2)$ & $153(16.6)$ \\
\hline Marginal (<1 ha) & $83(10.1)$ & $743(80.7)$ \\
\hline Small (1 to <2 ha) & $213(25.9)$ & $20(2.2)$ \\
\hline Semi-Medium ( 2 to $<4$ ha) & $155(18.9)$ & $5(0.5)$ \\
\hline Medium ( 4 to $<10 \mathrm{ha}$ ) & $60(7.3)$ & 0 \\
\hline Large (10 ha \& above) & $5(0.6)$ & 0 \\
\hline \multicolumn{3}{|c|}{ Home Garden } \\
\hline Yes & $124(15.1)$ & $446(48.1)$ \\
\hline No & $698(84.9)$ & $475(51.6)$ \\
\hline \multicolumn{3}{|c|}{ House Type } \\
\hline Kuccha & $414(50.4)$ & $524(56.9)$ \\
\hline Semi-Pucca & $352(42.8)$ & $379(41.2)$ \\
\hline Pucca & $56(6.8)$ & $18(2.0)$ \\
\hline \multicolumn{3}{|c|}{ Food Expenditure (Rs.) } \\
\hline$<1000$ & $35(4.3)$ & $285(30.9)$ \\
\hline 1000 to $<2000$ & $315(38.3)$ & $509(55.3)$ \\
\hline 2000 to $<3000$ & $338(41.1)$ & $101(11.0)$ \\
\hline$>=3000$ & $134(16.3)$ & $26(2.8)$ \\
\hline
\end{tabular}

Figure in parenthesis denotes percentages; Source: Bhaskar et al. [12]. 
in Koraput. As mentioned earlier both the locations are rainfed areas. Most of the households in Wardha did not have home gardens; however, $48 \%$ of households in Koraput had home gardens as it was a part of their socio-cultural practice.

Cultivation was the major occupation in both the locations followed by agriculture wage labour in Wardha and non agriculture wage labour in Koraput. About $37 \%$ of the households in Wardha were landless and 36\% were small land holder ( $<2$ ha). In Koraput, $83 \%$ of the households owned less than 2 hectare land.

Cotton, pigeon pea, soya bean, sorghum was grown in Kharif season (July-October during the south-west monsoon) and wheat and Bengal gram in Rabi (October-March (winter)) in Wardha. In Koraput, rice and finger millet were grown as Kharif crops and groundnut, greengram, maize, finger millet and black gram were grown as Rabi crops. Detailed characteristics of the study area and agricultural pattern are given in Bhaskar et al. [12].

\subsection{Food Consumption and Energy Intake Based on Agricultural Seasons}

The average intake of food groups and the energy provided by them and the percentage share of each food group to total energy intake per day based on agricultural seasons in Wardha and Koraput is shown in Table 2 and Table 3, respectively.

1) Wardha

Wheat followed by rice was the staple food in Wardha. In addition to cereals,

Table 2. Average intake (g/CU/day) of food groups, energy (kcal/CU/day) provided by foods and energy (\%) contributed by different food groups based on different agriculture seasons in Wardha.

\begin{tabular}{cccccccc}
\hline \multirow{2}{*}{ Food Groups } & \multicolumn{3}{c}{ Average Intake of Foods (g/CU/day) } & \multicolumn{4}{c}{ Average Energy Intake (kcal/ CU/day) } \\
\cline { 2 - 8 } & Harvest & Lean & Planting & RDI $^{*}$ & Harvest & Lean & Planting \\
\hline Cereals \& Millets & 425.4 & 464.6 & 349.5 & 375 & $1456.0(62.3)$ & $1588.8(64.3)$ & $1195.3(62.5)$ \\
Pulses \& Legumes & 59.0 & 40.6 & 44.1 & 75 & $187.6(8.0)$ & $141.4(5.7)$ & $151.7(7.9)$ \\
Vegetables & 184.4 & 160.8 & 142.5 & $500^{\sharp}$ & $87.5(3.7)$ & $78.8(3.2)$ & $62.0(3.2)$ \\
Fruits & $35.7^{\mathrm{a}}$ & $36.8^{\mathrm{a}}$ & 30.2 & 100 & $17.9^{\mathrm{a}}(0.8)$ & $20.1^{\mathrm{a}}(0.8)$ & $15.7(0.8)$ \\
Animal Foods & 77.4 & 65.1 & 76.6 & $100^{\$}$ & $67.4(2.9)$ & $57.6^{\mathrm{a}}(2.3)$ & $58.1^{\mathrm{a}}(3.0)$ \\
Edible fats \& Oils & 38.7 & 42.9 & 28.4 & 25 & $342.7(14.7)$ & $386.0(15.6)$ & $255.4(13.4)$ \\
Sugars & $44.5^{\mathrm{ab}}$ & $50.2^{\mathrm{a}}$ & $43.8^{\mathrm{b}}$ & 20 & $176.7^{\mathrm{ab}}(7.6)$ & $198.9^{\mathrm{a}}(8.0)$ & $172.8^{\mathrm{b}}(9.0)$ \\
& \multicolumn{2}{c}{ Total } & & & 2335.8 & 2471.6 & 1910.9 \\
& & & & & $\mathrm{RDA}^{\star} 2320$ & \\
\hline
\end{tabular}

Source: FSN baseline study (2013-15); Figures in parenthesis represent percentages; CU: consumption unit. *Recommended Dietary Intake (RDI) \& Recommended Dietary Allowance (RDA) given by National Institute of Nutrition, Indian Council of Medical Research, Hyderabad; ${ }^{*} 100$ g green leafy vegetables, 200 g roots and tubers, $200 \mathrm{~g}$ other vegetables; ${ }^{\$}$ Fish and sea foods and meat and poultry (no RDI); milk and milk products (100g RDI); ${ }^{a b}$ alphabets represent the non significance; otherwise significance @ $p<0.05$. 
Table 3. Average intake (g/CU/day) of food groups, energy (kcal/CU/day) provides by foods and energy (\%) contributed by different food groups based on different agriculture seasons in Koraput.

\begin{tabular}{cccccccc}
\hline \multirow{2}{*}{ Food Groups } & \multicolumn{9}{c}{ Average Intake of Foods (g/CU/day) } & \multicolumn{4}{c}{ Average Energy Intake (kcal/ CU/day) } \\
\cline { 2 - 8 } & Harvest & Lean & Planting & RDI $^{*}$ & Harvest & Lean & Planting \\
\hline Cereals \& Millets & 497.5 & 521.7 & 613.3 & 375 & $1680.5(83.1)$ & $1784.1(86.3)$ & $2091.8(84.0)$ \\
Pulses \& Legumes & $21.4^{\mathrm{a}}$ & 14.8 & $22.1^{\mathrm{a}}$ & 75 & $74.6^{\mathrm{a}}(3.7)$ & $51.0(2.5)$ & $76.0^{\mathrm{a}}(3.1)$ \\
Vegetables & $230.4^{\mathrm{a}}$ & 253.3 & $238.5^{\mathrm{a}}$ & $500^{\sharp}$ & $113.5(5.6)$ & $107.8(5.2)$ & $128.7(5.2)$ \\
Fruits & 8.2 & 10.8 & 71.2 & 100 & $7.8(0.4)$ & $9.7(0.5)$ & $42.9(1.7)$ \\
Animal Foods & $22.2^{\mathrm{a}}$ & $19.6^{\mathrm{a}}$ & 37.0 & $100^{\S}$ & $26.9(1.3)$ & $23.9(1.2)$ & $42.6(1.7)$ \\
Edible Fats \& Oils & 8.0 & $6.0^{\mathrm{a}}$ & $6.0^{\mathrm{a}}$ & 25 & $71.9(3.6)$ & $54.3^{\mathrm{a}}(2.6)$ & $54.3^{\mathrm{a}}(2.2)$ \\
Sugars & 11.7 & 9.2 & 13.3 & 20 & $46.3(2.3)$ & $36.4(1.8)$ & $52.9(2.1)$ \\
& \multicolumn{2}{c}{ Total } & & & 2021.5 & 2067.2 & 2489.2 \\
& & & & & $\mathrm{RDA}^{*} 2320$ & \\
\hline
\end{tabular}

Source: FSN baseline study (2013-15); Figures in parenthesis represent percentages; CU: consumption unit. ${ }^{*}$ Recommended Dietary Intake (RDI) \& Recommended Dietary Allowance (RDA) given by National Institute of Nutrition, Indian Council of Medical Research, Hyderabad; ${ }^{*} 100 \mathrm{~g}$ green leafy vegetables, $200 \mathrm{~g}$ roots and tubers, $200 \mathrm{~g}$ other vegetables; ${ }^{s}$ Fish and sea foods and meat and poultry (no RDI); milk and milk

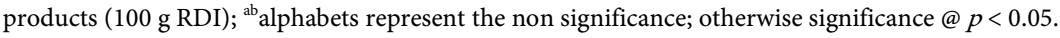

their daily diet consisted of pulses and legumes, roots and tubers, oil and sugars. Vegetables like onions, potatoes and brinjal, tomatoes and fruits like lemon were majorly consumed. It was observed that Wardha has a cereal based diet and cereals were consumed in higher amount than the recommended levels during harvesting and lean seasons. But it was lesser during planting season; this may be because Wardha has a commercial cropping pattern and expenditure on inputs for the cultivation of commercial crops compromise food expenditure. However, in lean season when the availability was less, foods were procured from PDS. Fats and sugars were consumed in higher quantities, more than the recommended levels irrespective of seasons; only during planting season consumption was slightly lesser than the recommended levels. High priced foods like pulses, vegetables and animal foods were consumed in higher quantities during harvesting season, due to the availability of money by selling their commercial produce. Similar result of higher consumption of vegetables during harvesting season irrespective of their source was reported by Locke et al. [6].

Significant difference was observed between the mean quantities of foods consumed between agricultural seasons and the energy provided by the food groups except for fruits (between harvest and lean period) and sugars (between harvest and lean period; planting and harvesting period) (Table 2). The energy provided by animal source foods in lean and planting period was same and lesser when compared to harvest season.

Overall in Wardha, the average consumption of cereals was $413 \mathrm{~g} / \mathrm{CU} /$ day, which provided $1413 \mathrm{kcal} / \mathrm{CU} /$ day and $63 \%$ of total energy intake/day. Kearney [15] reported that cereals continue to remain the most important food source 
and contributed 70 per cent of energy intake in parts of Asia. The remaining energy was contributed by fats (15\% of total energy/CU/day), sugars ( $8 \%$ ), pulses (7\%) and vegetables (5\%). The total energy intake was lowest during planting season (1911 kcal/CU/day) due to less food availability as well as less time diverted towards food preparation, as the period coincides with peak agricultural seasonality such as field preparation, sowing, planting, weeding, spraying etc. The inverse relationship of energy demand with food supply was also reported by Kigutha [4].

However, the energy intake met the RDA during harvesting and lean period mainly due to greater availability of foods. Stelmach-Mardas et al. [16] also reported that post harvest season is associated with increased energy intake.

2) Koraput

Similar to Wardha, the diet is cereal based in Koraput. Households have rice as staple food followed by finger millet and were consumed at higher quantities. Consumption of all other food groups was less than recommended levels. In contrast to Wardha, higher quantities of cereals, pulses, fruits, animal foods were consumed during planting season, while vegetables were consumed in higher quantities during lean period. Fats and oils were consumed in higher quantities during harvest season, as they were more affordable during this period.

There was significant difference between the mean quantities of foods consumed between agricultural seasons and the energy provided by the foods except for pulses and vegetables (between planting and harvest), animal foods (between harvesting and lean) and fats and oils (between lean and planting) (Table 3).

In Koraput, the average consumption of cereals and millets was $544 \mathrm{~g} / \mathrm{CU} /$ day which provided $1852 \mathrm{kcal} / \mathrm{CU} /$ day and contributed $85 \%$ of total energy. Remaining energy was contributed by vegetables (5\%) and pulses, sugars and fats ( $3 \%$ each). Highest energy intake was seen during harvesting season as the availability of foods is surplus. Tetens et al. [17] reported similar situation in Bangladesh that the dietary energy contribution from rice was $80 \%$ in both lean and peak seasons. Teokul, et al. [18] reported that there was less variation between seasons if there was a single crop; for example, in Bangladesh where there are two rice crops each year, the variations in food intake are much less. For rural households in Ethiopia, the mean daily per capita energy intake was $2459 \mathrm{kcal}$ in February (post-harvest period) and lower at $2319 \mathrm{kcal}$ in June (lean season) [7].

Overall, there was not much change in the percentage contribution of different food groups to the total energy intake in different seasons; however fluctuation was seen in quantities and the energy contributed by each food group in both study areas.

Seasonal variation in food intake and consumption at less than the recommended levels in Swazi households was demonstrated by Huss-Ashmore and Curry [19]. Tetens et al. [17] stated that the energy intake particularly in children and adolescents of Bangladesh, were significantly higher in the peak seasons (post harvest), when the food was abundant and rice prices were low than in lean 
season.

Figure 2 shows the mean difference of energy intake in a season from average intake during the year i.e. across 3 seasons. It can be observed that in Koraput, during harvest season, the energy intake was deficit (-171.2 kcal/CU/day) followed by lean season $(-125.5 \mathrm{kcal} / \mathrm{CU} / \mathrm{day})$, the reason being availability and affordability. Rossato et al. [20] reported higher carbohydrate intake in summer over other seasons in Brazilian adults.

In contrast to Koraput, in Wardha, positive energy intake $(+232.1 \mathrm{kcal} / \mathrm{CU} /$ day $)$ was observed during lean season followed by harvest season $(+96.4 \mathrm{kcal} / \mathrm{CU} /$ day $)$. The intake of energy was deficit by $-328.5 \mathrm{kcal} / \mathrm{CU} /$ day, during planting season. The rainy season is the time of year when food is most needed for work, but it is also the hungry season when food is shortest and most expensive [21].

Murayama and Ohtsuka [22] demonstrated that inter-season differences of mean total energy intake were significant between pre-harvest and harvest seasons and between harvest and rainy seasons among women farmers $(+1.08 \mathrm{MJ}$ and $-0.69 \mathrm{MJ}$, respectively).

\subsection{Relationship between Landholding and Agricultural Seasons on Energy Intake}

Association of land size and agriculture seasons on energy intake is given in Figure 3.

Earlier studies had demonstrated the relationship between landholding and food security. Muraoka et al. [23] demonstrated that a $10 \%$ increase in operational land size increased per capita total consumption and per capita home-produced food consumption by $0.8 \%$ and $2 \%$, respectively. In the present study, the mean energy intake during harvesting season in households having more than 2 hectares of land was higher in Wardha followed by landless and those with less than 2 hectare of land. During lean and planting period, energy intake was high in landless households followed by households having more than 2 hectare land. This might be due to engagement of landless households in

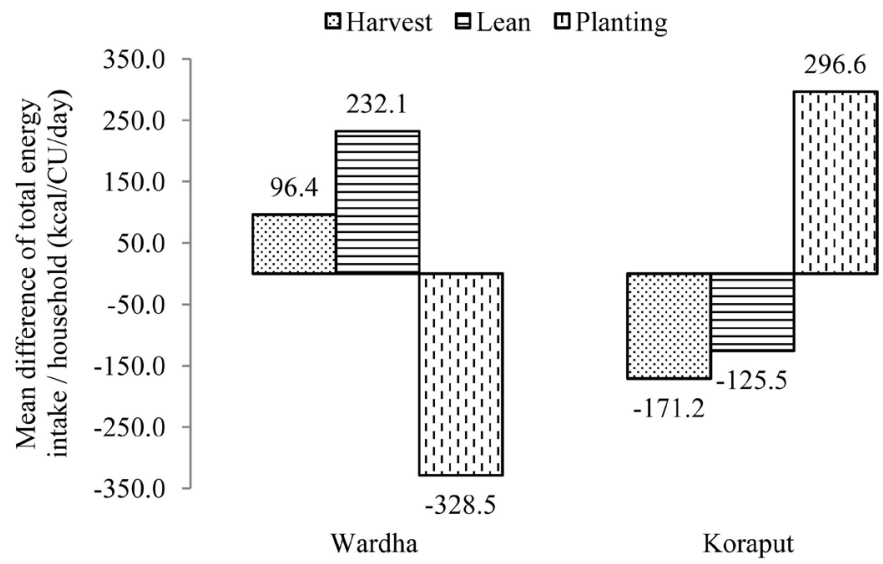

Figure 2. Mean difference in total average energy intake (kcal/CU/day) across agricultural seasons. 


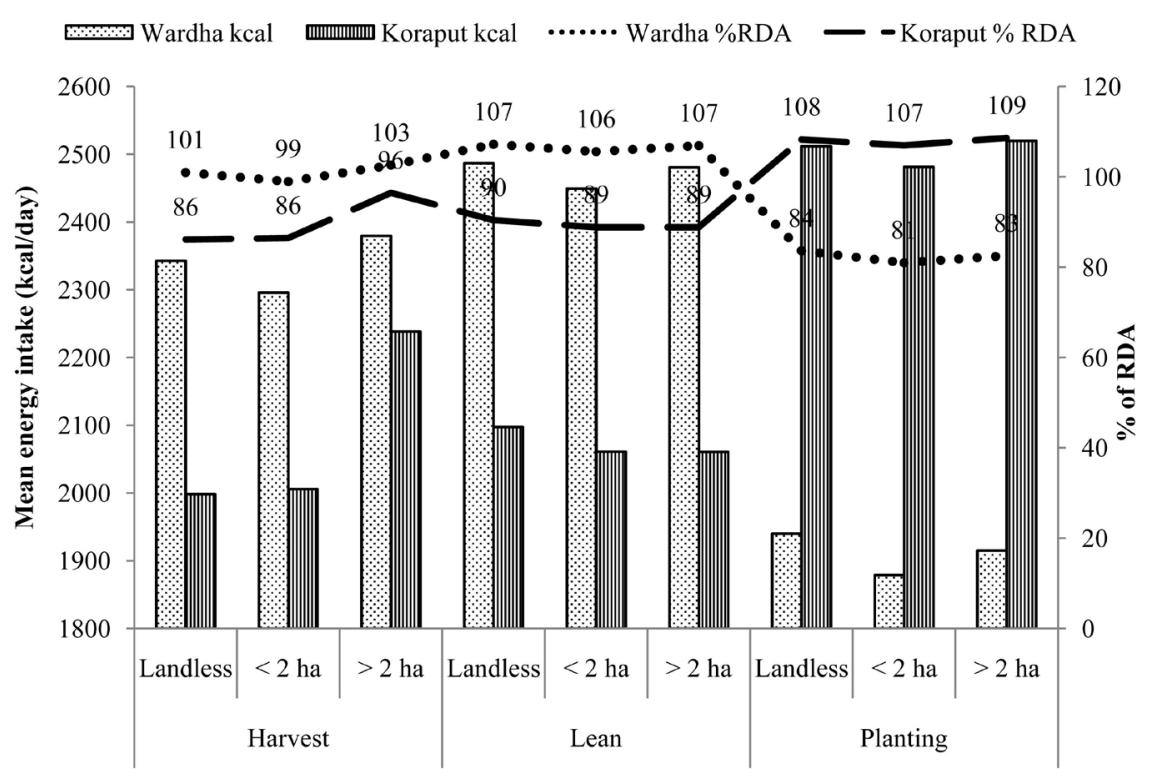

Figure 3. Mean energy intake (kcal/CU/day) and percentage of RDA depending on agriculture seasons and land size.

non-agricultural activities during lean periods and waged agricultural activities during peak periods, thereby not being affected by agricultural seasons. In many societies, the better-off farmers hired people from lower socioeconomic strata to do the agricultural work [2] and labourers benefit being able to get work. Access to off-farm or non-agricultural employment and income sources have smoothing effects on adverse seasonality [21]. Handa and Mlay [5] also reported that households with off-farm employment display less seasonal variation in consumption over the year compared to households without an off farm income source. Overall, the small and marginal land holders having less than 2 hectares of land were having lesser energy intake across all agricultural seasons. Herrero [24] reported small holders were the most affected by food insecurity and indicated small farm sector as a crucial entry point for policy interventions to improve food security and nutrition. The pre-harvest crisis might sometimes be more acute for self-provisioning small farm families than for landless labourers as the small farm families rely on their harvest for food and income, and may be driven to employ labour at a time when they are very short of money [21].

In Koraput, households having more than 2 hectare land consumed more energy during planting season followed by harvest season, than landless and households having less than 2 hectare of land. In lean season, the landless consumed more energy than land holders.

Overall, in Wardha, the landless households and more than 2 ha land holders consumed the recommended levels of energy intake during harvest and lean period and consumed $84 \%$ and $83 \%$ of RDA respectively; while, the households having $<2$ ha land consumed energy that met $81 \%$ during planting period. In Koraput, during planting period, the energy intake met RDA, irrespective of land holding size. Energy intake was $86 \%$ of RDA during harvest period by 
landless and less than 2 ha land holders, while it was $96 \%$ of RDA by more than 2 ha land holders; while in lean period, it was $88 \%$ of RDA by land holders and $90 \%$ of RDA by landless households. Singh et al. [25] reported consumption of $92 \%$ of RDA by landless agricultural wage labourer followed by small farmers ( $90 \%$ of RDA) and medium farmers ( $84 \%$ of RDA) in lean season and $94 \%$ RDA by landless agricultural wage labourer, $93 \%$ RDA by small farmers and $87 \%$ of RDA by medium farmers in peak season.

\subsection{Effect of Agricultural Seasons on Sourcing of Food and Energy}

Comparatively, Koraput being a subsistence farming area, the sourcing of foods from own production was more prevalent than in Wardha where commercial farming system dominates and there is more dependence on market. Sharing and exchange of foods among households was found to be less in both locations irrespective of seasons. Although the villages were near the forest, the collection and consumption of wild foods were negligible, with minimal contribution towards total energy intake. Public distribution system (PDS) with rice at Rs.2/kg being given in Koraput and Wardha and wheat at Rs.3/kg in Wardha, played a wide role in both locations irrespective of agricultural seasons.

In Koraput, major proportion of energy intake was sourced from PDS and market (63\% of RDA in harvesting; $70 \%$ in lean; $74 \%$ in planting) followed by PDS alone or PDS and home grown whereas in Wardha, its inverse, the households depend mostly on PDS and home grown (57\% of RDA in harvesting; $48 \%$ in lean; $32 \%$ in planting) followed by PDS and market and PDS alone for their energy requirements.

Figure 4 shows the energy obtained from different sources and the percentage contribution against RDA.

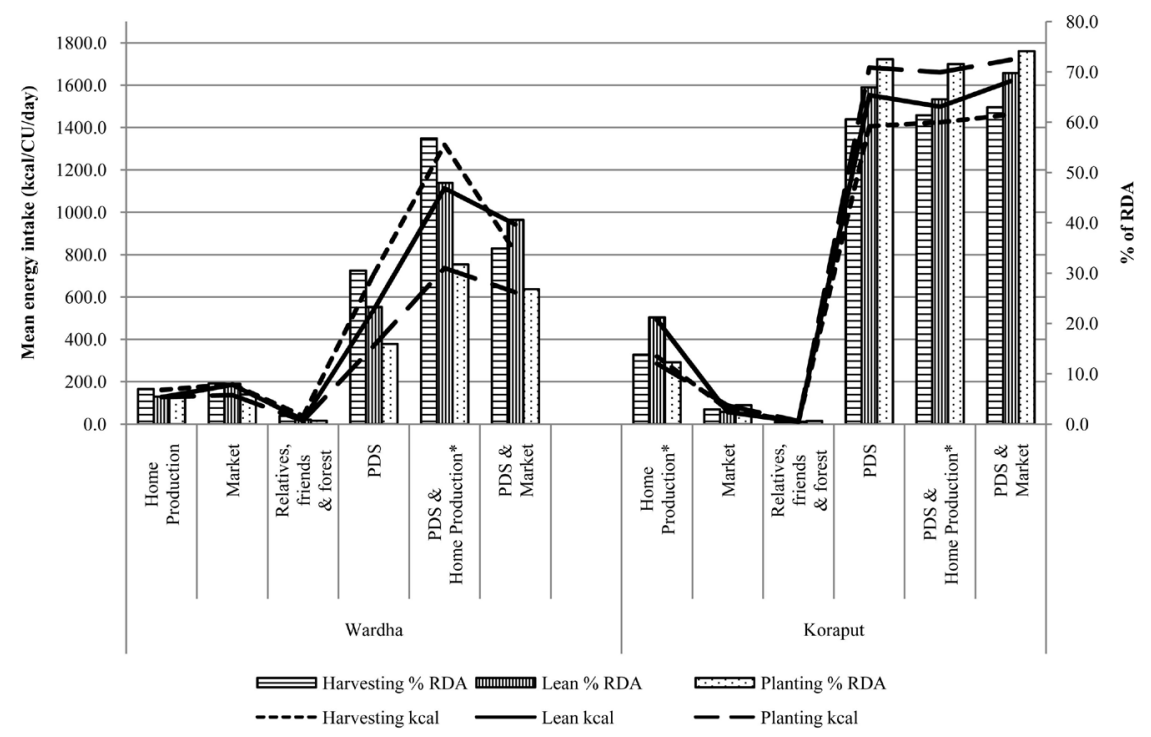

Figure 4. Mean energy intake (kcal/CU/day) obtained from different sources and the percentage of RDA based on agricultural seasons. *backyard or own field production; \#neighbours, relatives or forest. 
Sibhatu and Qaim [26] reported that in Ethiopia, the average, subsistence production accounted for $58 \%$ of rural households' calorie consumption; $42 \%$ of the calories consumed were from purchased foods; during the lean season, purchased foods accounted for more than half of all calories consumed.

\section{Conclusions}

The results of the present study show that seasonality plays a wider role on the energy intake from different food groups and from different sources. In addition to seasonality, land size also affects the energy intake across all seasons. The type of farming system, subsistence or commercial, also showed effect on the energy intake; Wardha having a commercial cropping pattern showed positive during harvest season followed by lean and was negative during planting season. Koraput having a subsistence farming system showed higher energy intake during planting season. In both locations, pulses, vegetables, fruits, fish, meat and milk consumption was less than RDI consumed. Government initiative particularly public distribution system helps in steady supply of cereals (rice and wheat) irrespective of seasons.

Seasonality in agriculture production implies fluctuations in food supply and food availability. After the harvest, during lean period, there is usually enough food for some time which is demonstrated in Wardha. But during the following wet season food stocks slowly get depleted with food becoming scare during the next few months before the harvest begins particularly in areas having unimodal climates [2]. One rainy and one harvest season a year, reduce the optimal period for plant growth and thereby oblige the farming communities to engage in short intensive bouts of agricultural activities. The period of intensive agricultural work coincides with the time of the year when food stocks at the household are at their lowest levels, lean season followed by planting season. By influencing food availability and activity patterns, seasonality affects energy and nutrients intakes, as well as the energy expenditure and the nutritional status. Seasonal variation in food availability has long been recognized as a contributor to energy and thereby influencing nutrition. Overall the study findings contribute to the growing literature that attempts to understand the role of food intake in improving food and nutrition security across seasons particularly in a population dependent on agriculture for livelihood.

\section{Acknowledgements}

Authors are thankful to LANSA team, India for their contribution to the paper: Dr. R. V. Bhavani for overall coordination, Mr. Akshaya Kumar Panda and Ms. Jasaswani Padhi for data collection in Koraput and Mr. Mahesh Maske and Ms. Rupal Wagh for data collection in Wardha. This research is part of the data generated by the Leveraging Agriculture for Nutrition in South Asia Research (LANSA) research consortium, and is funded by UK Aid from the UK government. The views expressed do not necessarily reflect the UK Government's official policies. 


\section{References}

[1] Ferro-Luzzi, A., Branca, F. and Pastore, G. (1994) Body Mass Index Defines the Risk of Seasonal Energy Stress in the Third World. European Journal of Clinical Nutrition, 48, S165-S178.

[2] Wandel, M. and Holmboe-Ottesen, G. (1992) Food Availability and Nutrition in a Seasonal Perspective: A Study from the Rukwa Region in Tanzania. Human Ecology, 20, 89-107. https://doi.org/10.1007/BF00889697

[3] NSSO (2013) Key Indicators of Situation of Agricultural Households in India. http://mospi.nic.in/sites/default/files/publication_reports/KI_70_33_19dec14.pdf

[4] Kigutha, H.N. (1994) Household Food Security and Nutritional Status of Vulnerable Groups in Kenya: A Seasonal Study among Low Income Smallholder Rural Households. https://idl-bnc-idrc.dspacedirect.org/handle/10625/14257

[5] Handa, S. and Mlay, G. (2006) Food Consumption Patterns, Seasonality and Market Access in Mozambique. Development Southern Africa, 23, 541-560. https://doi.org/10.1080/03768350600929249

[6] Locke, E., Coronado, G.D., Thompson, B. and Kuniyuki, A. (2009) Seasonal Variation in Fruit and Vegetable Consumption in a Rural Agricultural Community. Journal of the American Dietetic Association, 109, 45-51. https://doi.org/10.1016/j.jada.2008.10.007

[7] Hirvonen, K., Taffesse, A.S. and Worku Hassen, I. (2016) Seasonality and Household Diets in Ethiopia. Public Health Nutrition, 19, 1723-1730. https://doi.org/10.1017/S1368980015003237

[8] Tokudome, Y., Imaeda, N., Nagaya, T., Ikeda, M., Fujiwara, N., Sato, J., Kuriki, K., Kikuchi, S., Maki, S. and Tokudome, S. (2002) Daily, Weekly, Seasonal, Within- and Between-Individual Variation in Nutrient Intake According to Four Season Consecutive 7 Day Weighed Diet Records in Japanese Female Dietitians. Journal of Epidemiology, 12, 85-92. https://doi.org/10.2188/jea.12.85

[9] Shively, G.E. and Hao, J. (2012) A Review of Agriculture. Food Security and Human Nutrition Issues in Uganda. Working Paper \#12-3, Department of Agricultural Economics, Purdue University. http://ageconsearch.umn.edu/record/135134

[10] Pastore, G., Branca, F., Demissie, T. and Ferro-Luzzi, A. (1993) Seasonal Energy Stress in an Ethiopian Rural Community: An Analysis of the Impact at the Household Level. European Journal of Clinical Nutrition, 47, 851-862.

[11] Tin-May-Than and Ba-Aye. (1985) Energy Intake and Energy Output of Burmese Farmers at Different Seasons. Human Nutrition Clinical Nutrition, 39, 7-15.

[12] Bhaskar, A.V.V., Nithya, D.J., Raju, S. and Bhavani, R.V. (2017) Establishing Integrated Agriculture-Nutrition Programmes to Diversify Household Food and Diets in Rural India. Food Security, 9, 981-999.

https://doi.org/10.1007/s12571-017-0721-Z

[13] Das, P.K., Bhavani, R.V. and Swaminathan, M.S. (2014) A Farming System Model to Leverage Agriculture for Nutritional Outcomes. Agricultural Research, 3, 193-203. https://doi.org/10.1007/s40003-014-0119-5

[14] Nagarajan, S., Bhavani, R.V. and Swaminathan M.S. (2014) Operationalizing the Concept of Farming System for Nutrition through the Promotion of Nutrition-Sensitive Agriculture. Current Science, 107, 959-964.

[15] Kearney, J. (2010) Food Consumption Trends and Drivers. Philosophical Transactions of the Royal Society B: Biological Sciences, 365, 2793-2807.

https://doi.org/10.1098/rstb.2010.0149 
[16] Stelmach-Mardas, M., Kleiser, C., Uzhova, I., Peñalvo, J.L., La Torre, G., Palys, W., Lojko, D., Nimptsch, K., Suwalska, A., Linseisen, J., Saulle, R., Colamesta, V. and Boeing, H. (2016) Seasonality of Food Groups and Total Energy Intake: A Systematic Review and Meta-Analysis. European Journal of Clinical Nutrition, 70, 700-708. https://doi.org/10.1038/ejcn.2015.224

[17] Tetens, I., Hels, O., Khan, N.I., Thilsted, S.H. and Hassan, N. (2003) Rice-Based Diets in Rural Bangladesh: How Do Different Age and Sex Groups Adapt to Seasonal Changes in Energy Intake? The American Journal of Clinical Nutrition, 78, 406-413. https://doi.org/10.1093/ajcn/78.3.406

[18] Teokul, W., Payne, P. and Dugdale, A. (1986) Seasonal Variations in Nutritional Status in Rural Areas of Developing Countries: A Review of the Literature. Food and Nutrition Bulletin, 8, 7-10.

[19] Huss-Ashmore, R. and Curry, J.J. (1991) Diet, Nutrition, and Agricultural Development in Swaziland. 2. Patterns of Food Consumption. Ecology of Food and Nutrition, 26, 167-185. https://doi.org/10.1080/03670244.1991.9991200

[20] Rossato, S.L., Olinto, M.T.A., Henn, R.L., dos Anjos, L.A., Bressan, A.W. and Wahrlich, V. (2010) Seasonal Effect on Nutrient Intake in Adults Living in Southern Brazil. Cadernos de Saúde Pública, 26, 2177-2187.

https://doi.org/10.1590/S0102-311X2010001100019

[21] Chambers, R., Longhurst, R. and Pacey, A. (1981) Seasonal Dimensions to Rural Poverty. Frances Pinter (Publishers) Limited, London. http://citeseerx.ist.psu.edu/viewdoc/download?doi=10.1.1.472.5420\&rep=rep1\&type $=\mathrm{pdf}$

[22] Murayama, N. and Ohtsuka, R. (1999) Seasonal Fluctuation in Energy Balance among Farmers in Northeast Thailand: The Lack of Response of Energy Intake to the Change of Energy Expenditure. European Journal of Clinical Nutrition, 53, 39-49. https://doi.org/10.1038/sj.ejcn.1600675

[23] Muraoka, R., Jin, S. and Jayne, T.S. (2014) Land Access, Land Rental and Food Security: Evidence from Kenya. The Agricultural \& Applied Economics Association, Minneapolis.

[24] Herrero, M., Thornton, P.K., Notenbaert, A.M., Wood, S., Msangi, S., Freeman, H.A., Bossio, D., Dixon, J., Peters, M., van de Steeg, J., Lynam, J., Parthasarathy Rao, P., Macmillan, S., Gerard, B., McDermott, J., Seré, C. and Rosegrant, M. (2010) Smart Investments in Sustainable Food Production: Revisiting Mixed Crop-Livestock Systems. Science, 327, 822-825. https://doi.org/10.1126/science.1183725

[25] Singh, S., Sinwal, S. and Rathore, H. (2012) Assessment of Energy Balance of Indian Farm Women in Relation to Their Nutritional Profile in Lean and Peak Agricultural Seasons. Work, 41, 4363-4371.

[26] Sibhatu, K.T. and Qaim, M. (2017) Rural Food Security, Subsistence Agriculture, and Seasonality. PLOS ONE, 12, e0186406.

https://doi.org/10.1371/journal.pone.0186406 